\title{
Flower of Typha latifolia as a Low-cost Adsorbent for Quantitative Uptake of Multiclass Pesticide Residues from Contaminated Waters
}

\author{
Teshome Tolcha ${ }^{(1 D}$, Tura Gemechu and Negussie Megersa* \\ Department of Chemistry, Addis Ababa University, P. O. Box 1176, Addis Ababa, Ethiopia. \\ Received 25 July 2019, revised 13 January 2020, accepted 14 January 2020.
}

\begin{abstract}
The quantitative removal of atrazine, diazinon, chlorothalonil, ametryn, chlorpytrifos and dimethametryn from contaminated water was studied using flower of the Typha latifolia. The surface chemistry of this adsorbent was analyzed by FT-IR and the adsorption efficiency was studied using batch adsorption technique. The potential experimental parameters studied were $\mathrm{pH}(5-9)$, the dose of adsorbent (0.1-0.5 g), contact time (100-140 min), shaking speed (100-300 rpm) and initial pesticide concentration (3.15-100 $\left.\mu \mathrm{g} \mathrm{L}^{-1}\right)$. The effects of concentration and contact time at the optimum conditions were used to study equilibrium and kinetic models for pesticide sorption. Results of the sorption equilibria were found to fit better to the Langmuir isotherm model than the Freundlich adsorption model indicating monolayer homogeneous surface conditions. On the other hand, kinetics of all pesticides sorption on the adsorbent was well defined by the pseudo-second-order model. The results obtained showed that the use of this plant be considered as one of the promising, natural, easily accessible and low-cost adsorbent for efficient and quantitative removal of pesticides from contaminated water.
\end{abstract}

\section{KEYWORDS}

Adsorption efficiency, contaminated water, low-cost adsorbent, multiclass pesticide residues, sample preparation, Typaha latifolia.

\section{Introduction}

The increasing use of pesticides in agriculture for controlling pests to ensure food security make a serious contribution to increased levels of pesticide residues in environment, particularly water resources. ${ }^{1,2}$ The application of these compounds and their degradation products has the possibility of contaminating ground and surface waters, ${ }^{3,4}$ soil and sediments. ${ }^{5}$ The leaching of pesticides receives particular attention because it directly influences the extent of surface and ground water contamination. 6,7

The chemical pesticides are potential hazard to the environment and public health due to their toxicity in the original form and their degradation products. ${ }^{3}$ In the European Community, the maximum residue level of these compounds in water for human consumption is $0.1 \mu \mathrm{g} \mathrm{L}^{-1}$ for each individual and $0.5 \mu \mathrm{g} \mathrm{L}{ }^{-1}$ for total pesticides. ${ }^{4}$ Due to the distressing effects of pesticides, researchers have focusing on the reduction of using pesticides and develop treatment methods to remove them from water. Several conventional treatment methods for pesticides removal from contaminated water has been used including photocatalytic degradation, combined photo-Fenton and biological oxidation, advanced oxidation processes, nanofiltration and ozonation. ${ }^{8-10}$ These methods are very expensive. Thus, there is a need for green and advanced pesticide removal to meet environmental quality requirements improving ecological system. Adsorption has evolved into one of the most effective processes for pesticide removal because the technique uses equipment that is readily available, easy to use, energetically not intensive and of low cost. ${ }^{11}$ In this regard, adsorbents of natural origin become attractive due to their availability, high adsorption capacity, low cost and minimization of chemical and/or biological sludge regeneration. ${ }^{12}$

* To whom correspondence should be addressed.

E-mail: negussie.megersa@ aau.edu.et
In the past decades, a variety of techniques have been developed for treatment of water contaminated by pesticides. A multi-walled carbon nanotubes was used for removal of malathion, ${ }^{7}$ activated carbon for 2,4-D ${ }^{13}$ and deethylatrazine, deisopro-pylatrazine (deethylsimazine) and deethylcyanazine, ${ }^{14}$ chest nut for carbofuran and methyl parathion, ${ }^{3}$ straw for methyl parathion ${ }^{15}$ and tea waste for malathion and phorate. ${ }^{16}$ The removal efficiency of the lignocellulosic substrate from agroindustry for dieldrin and chlorpyrifos, ${ }^{6}$ baggasse fly ash for lindane and malathion, ${ }^{17}$ coal fly ash and herbal leaves powder for carbary $1^{18,19}$ and rice husk, sunflower seed shells, an agricultural soil and composted sewage sludge for chlorfenvinphos, chlorpyrifos, simazine and trifluralin ${ }^{12}$ was also evaluated.

Even though, a number of wastewater treatment methods have been developed in recent years, still a research gap is significant with reference to the exploration of the adsorption capabilities of Typha latifolia as low-cost adsorbents for the simultaneous removal of multiclass pesticides residues including atrazine, diazinon, chlorothalonil, ametryn, malathion, chlorpyrifos and dimethametryn. Typha latifolia plants, commonly known as cattails, are grown in a mixture of mature sewage sludge compost, commercial compost and perlite..$^{20,21}$ The use of wetland plants, Typha latifolia, as adsorbent is economical, low technology method for the wastewater treatment. To the best of the authors' knowledge, no one has reported the use of this plant for the treatment of wastewater polluted by pesticides. Furthermore, the effects of various experimental parameters influencing the removal efficiency of the proposed adsorbent have been investigated. Evaluation of the adsorption potential of Typha latifolia was based on the removal percentage and adsorption capacity.

\section{Material and Methods}

2.1. Chemicals and Reagents

All the pesticide standards; atrazine, diazinon, chlorothalonil, 
ametryn, malathion, chloropyrifos and dimethametryn (Table 1) were obtained from Dr. Ehrenstorfer GmbH (Augsburg, Germany). Methanol from Acros Organics (New Jersey, USA) and chloroform from Sigma Aldrich (Seelze, Germany) were used as disperser and extraction solvent, respectively. To adjust the sample $\mathrm{pH}$ hydrochloric acid purchased from Sigma-Aldrich Chemie GmbH (Steinheim, Germany), and sodium hydroxide pellets from BDH Laboratory Supplies (Poole, England), were used. Stock standard solution, $100 \mathrm{mg} \mathrm{L}^{-1}$, each of the target compounds was prepared in methanol. Working solutions, containing a mixture of each analyte, of $10 \mathrm{mg} \mathrm{L}^{-1}$ were prepared from stock solution by diluting with methanol. All solutions were stored in the dark at $4{ }^{\circ} \mathrm{C}$ when not in use.

\subsection{Instrumentation}

Analysis of pesticides residue was performed using Agilent Technologies, 7820 A gas chromatograph (GC) equipped with Agilent Technologies, 5977 E inert mass spectrometer (MS) detector. GC column, DB-5MS ultra inert capillary column (30 $\mathrm{m} \times 250 \mu \mathrm{m}$ and $0.25 \mu \mathrm{m}$ i.d.), was used for separation of analytes under study. A flow rate of carrier gas, helium gas, was kept at a flow rate of $1 \mathrm{~mL} \mathrm{~min}^{-1}$ and the results were interpreted using Agilent mass hunter ChemStation. The GC injection port temperature was maintained at $250{ }^{\circ} \mathrm{C}$. The oven temperature programme used during separation were: $130^{\circ} \mathrm{C}$ for $0 \mathrm{~min}$; then increased at $25^{\circ} \mathrm{C} \mathrm{min}^{-1}$ to $185^{\circ} \mathrm{C}$ held for $1 \mathrm{~min}$; then increased at $9{ }^{\circ} \mathrm{C} \mathrm{min}-1$ to $200{ }^{\circ} \mathrm{C}$ for $1 \mathrm{~min}$ and $10{ }^{\circ} \mathrm{C} \mathrm{min}-1$ to $290{ }^{\circ} \mathrm{C}$ held for $1 \mathrm{~min}$. The splitless mode was used in all injections. The full scan mode was scanned over the range of $\mathrm{m} / \mathrm{z} 50-550$, to confirm retention time of each analyte. Then, selective ion monitoring (SIM) mode was used for the determination of all analytes. To confirm the pesticides the most abundant characteristic ions of each pesticide and two characteristic fragment ions were selected. The $m / z$ selected for SIM detection mode were: atrazine (215.1, 200.1, 173.1), diazinon (152.1, 137.1, 124.1), chlorothalonil $(267.9,265.9,263.9)$, ametryn (228.1, 227.1, 226.1), malathion (178.1, 174.1, 158.1), chloropyrifos $(198.9,196.9,179.1)$ and dimethametryn $(213.1,212.1,196.1) .{ }^{26}$ Origin 6.0 software was used for data analysis and a one-way ANOVA was used for statistical significance test $(\mathrm{P}>0.05)$. Adwa $\mathrm{pH}$ meter (AD1020 $\mathrm{pH} / \mathrm{mv} / \mathrm{ISE} /$ Temperature, Hungary) was used for the sample $\mathrm{pH}$ adjustment. Identification of the various functional groups of the Typha latifolia was carried out using Spectrum 65 FT-IR spectrometer (Perkin Elmer, USA). An orbital shaker (Model CHINCAN, WSZ-100, China) and centrifuge model 800 (China) were also used for mixing and centrifuging to effect separation of the adsorbent from the sample solution, respectively.

\subsection{Collection and Preparation of the Adsorbent}

The preparation method is the most important factor for any adsorbent, since morphological properties including particle binding surface area, size and shape, and overall removal capacity is determined by it. A hazard free, simple to prepare and use, and environment friendly treatments are the major requirements for sustainable preparation of biosorbent. Considering the above, this research used a simple and non-treated preparation methods rather than the expensive and high technology and non-environment friendly acid/base pre-treatment methods. ${ }^{27,28}$ The Typha latifolia plant samples were collected from the vicinity of Muger River, North Shoa, Oromia region, Ethiopia, using pre-cleaned polyethylene bags. The geographical location of sampling site is $9^{\circ} 54^{\prime} 00.43^{\prime \prime} \mathrm{N}$ latitude and $37^{\circ} 57^{\prime} 11.87^{\prime \prime} E$ longitude having elevation of $1548.38 \mathrm{~m}$ above the sea level. The Typha latifolia plant on the sampling site and its powdered flowers is shown in Fig. 1. The collected flower of the plant was air-dried and cut into small pieces. Then, it was washed with distilled water to remove dust particles and any impurities. After drying, the adsorbents were ground using electric mill and sieved using $300 \mu \mathrm{m}$ sieve particle size analyzer. The powdered adsorbents were dried at $105^{\circ} \mathrm{C}$ in an oven until constant mass of the powdered sample was obtained and stored in polyethylene bag until it is used in the adsorption process.

\subsection{Batch Adsorption Experiments}

Batch experiments using a series of $100 \mathrm{~mL}$ conical flask were carried out to study the effects of contact time, $\mathrm{pH}$, adsorbent dosage and initial pesticide concentrations on adsorption of the target pesticides from aqueous samples. A weighed amount $(0.4 \mathrm{~g})$ of the powdered biosorbent was added to the conical flask containing $50 \mathrm{~mL}$ of synthetic contaminated water samples adjusted to $\mathrm{pH} 6$ containing of known initial concentration of pesticides. Then, the resulting mixture was agitated at a $150 \mathrm{rpm}$ for $2 \mathrm{~h}$ on orbital shaker and the supernatant was filtered through Whatman No. 42 filter paper which was pre-saturated with distilled and deionized water. The pretreated wastewater should be subjected to sample preparation because it is incompatible with gas chromatography-mass spectrometry (GC-MS) for analysis of pesticide residues. For this reason, a $5 \mathrm{~mL}$ of the pretreated solution was adjusted to $\mathrm{pH} 7$ and then, a $40 \mu \mathrm{L}$ of mixture of chloroform and $0.4 \mathrm{~mL}$ methanol was injected into the sample solution, in the modified micropipette tip. The cloudy solution was stand for $3 \mathrm{~min}$ and centrifuged at $4000 \mathrm{rpm}$ for $3 \mathrm{~min}$. Then, from the extract $1 \mu \mathrm{L}$ was injected into a GC-MS system. ${ }^{26}$ The experiments were repeated in triplicate throughout to confirm the results and then average values are presented. The equilibrium pesticide residues concentrations levels were determined and expressed in terms of peak area using the GCMS. Finally, the signals obtained as peak area were computed in terms of the pesticide concentration using standard calibration curve. The percentage removal and adsorption capacity at equilibrium, $\mathrm{q}_{\mathrm{e}}\left(\mathrm{mg} \mathrm{g}^{-1}\right)$, of each pesticide was calculated using Equations 1 and 2 , respectively. ${ }^{12}$

Table 1 Physicochemical and physical constants of pesticides used in this study., 22-25

\begin{tabular}{|c|c|c|c|c|c|c|}
\hline Analyte & Molecular formula & $\begin{array}{l}\text { Molecular weight } \\
\qquad / \mathrm{g} \mathrm{mol}^{-1}\end{array}$ & $\begin{array}{l}\text { Solubility in water } \\
\qquad / \mathrm{mg} \mathrm{L}^{-1}\end{array}$ & $\begin{array}{l}\text { Density } \\
/ \mathrm{g} \mathrm{cm}^{-3}\end{array}$ & $\begin{array}{l}\mathrm{pKa} \\
/ 25^{\circ} \mathrm{C}\end{array}$ & $\begin{array}{l}\log \mathrm{P} \\
/ 25^{\circ} \mathrm{C}\end{array}$ \\
\hline Atrazine & $\mathrm{C}_{8} \mathrm{H}_{14} \mathrm{ClN}_{5}$ & 215.685 & $30\left(20^{\circ} \mathrm{C}\right)$ & 1.187 & 1.7 & -0.97 \\
\hline Diazinon & $\mathrm{C}_{12} \mathrm{H}_{21} \mathrm{~N}_{2} \mathrm{O}_{3} \mathrm{PS}$ & 304.35 & $40\left(25^{\circ} \mathrm{C}\right)$ & 1.12 & 2.6 & 3.69 \\
\hline Chlorothalonil & $\mathrm{C}_{8} \mathrm{Cl}_{4} \mathrm{~N}_{2}$ & 265.91 & $0.81\left(25^{\circ} \mathrm{C}\right)$ & 1.8 & - & 2.94 \\
\hline Ametryn & $\mathrm{C}_{9} \mathrm{H}_{17} \mathrm{~N}_{5} \mathrm{~S}$ & 227.33 & $185\left(20^{\circ} \mathrm{C}\right)$ & 1.190 & 4.1 & 2.63 \\
\hline Malathion & $\mathrm{C}_{10} \mathrm{H}_{19} \mathrm{O}_{6} \mathrm{PS}_{2}$ & 330.35 & $145\left(20^{\circ} \mathrm{C}\right)$ & 1.23 & 2.6 & 2.75 \\
\hline Chloropyrifos & $\mathrm{C}_{9} \mathrm{H}_{11} \mathrm{Cl}_{3} \mathrm{NO}_{3} \mathrm{PS}$ & 350.59 & $2\left(25^{\circ} \mathrm{C}\right)$ & 1.4 & - & 4.0 \\
\hline Dimethametryn & $\mathrm{C}_{11} \mathrm{H}_{21} \mathrm{~N}_{5} \mathrm{~S}$ & 255.38 & $19.6\left(25^{\circ} \mathrm{C}\right)$ & 1.11 & 4.0 & 3.9 \\
\hline
\end{tabular}



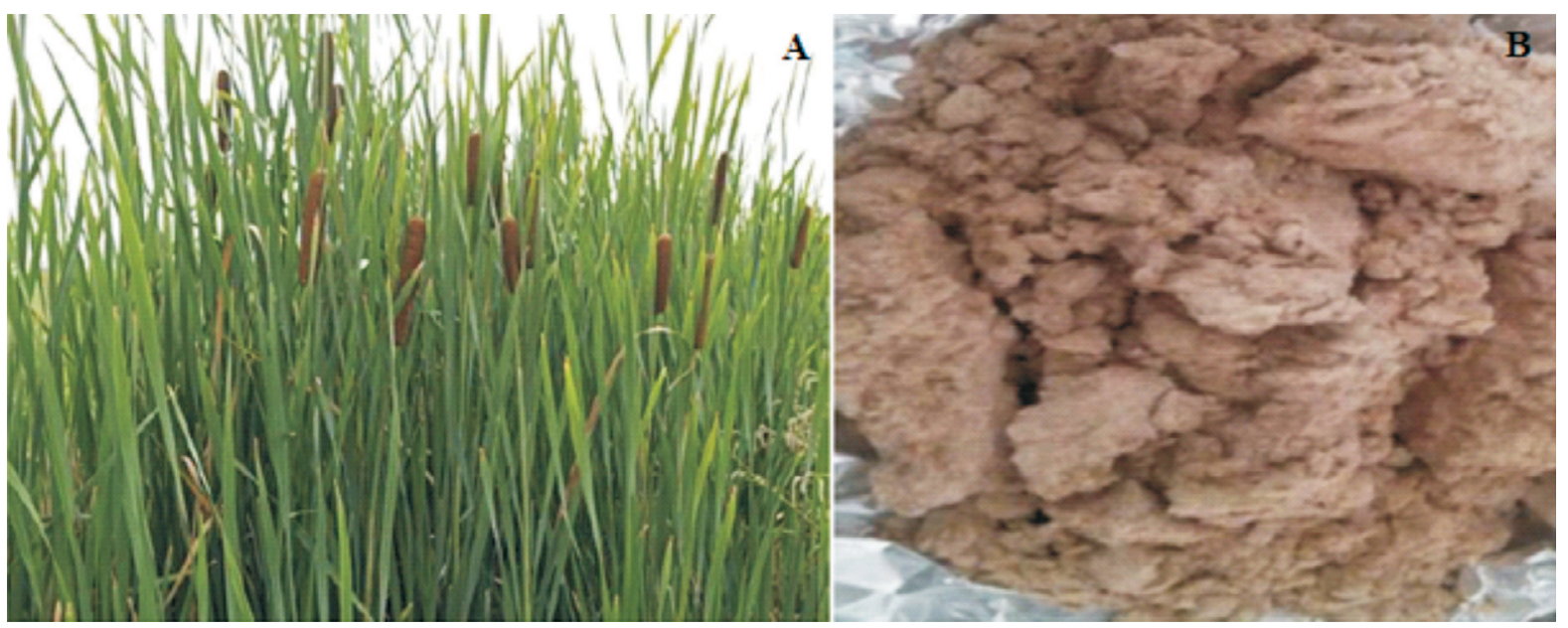

Figure 1 Typha latifolia at sampling site (A) and its powdered flowers (B).

$$
\begin{aligned}
& \text { Percentage removal }(\% \text { removal })=\frac{c_{i}-c_{e}}{c_{i}} \times 100 \\
& \text { Adsorption capacity }(q e)=\frac{c\left(c_{i}-c_{e}\right)}{m}
\end{aligned}
$$

where $\mathrm{C}_{\mathrm{i}}$ and $\mathrm{C}_{\mathrm{e}}\left(\mathrm{mg} \mathrm{L}^{-1}\right)$ are the initial and equilibrium concentration of the adsorbate in the solution, respectively, $\mathrm{V}$ is the volume of the solution $(\mathrm{mL})$ and $\mathrm{m}$ is the dry mass of adsorbent used in gram $(\mathrm{g})$.

\section{Results and Discussion}

\subsection{FTIR Analysis of Typha latifolia}

In order to examine the mechanism of adsorption process on the natural adsorbents, different functional groups found in the sorbent material are the key factors. To confirm the functional groups involved in pesticides uptake in the current adsorbent, the fresh and pesticide loaded adsorbent were mixed with spectroscopic grade $\mathrm{KBr}$ and made in the form of pellet. The pellet formed was scanned in the spectral range of $4000-400 \mathrm{~cm}^{-1} .^{29}$ The FT-IR spectra, Fig. 2, of flower of the adsorbent before (A) and after (B) pesticides uptake show a number of different absorption peaks, indicating the complex nature of adsorbent. As can be seen from the FT-IR spectra, the vibration bands of the adsorbent are due to the presence of hydrogen bonded $\mathrm{OH}$ stretch (alcohol) at $3410.5 \mathrm{~cm}^{-1}$, alkyl C-H stretching at $2918.5 \mathrm{~cm}^{-1}$ and alkenyl C-H stretch at $2850.5 \mathrm{~cm}^{-1}$. In addition, the absorption peaks at 1735,1606 and $1039.5 \mathrm{~cm}^{-1}$ are due to $\mathrm{C}=\mathrm{O}, \mathrm{C}=\mathrm{C}$ and $\mathrm{C}-\mathrm{O}$ functionalities, respectively. As shown in Fig. 2, the major absorption peaks of the adsorbent including fingerprint region, after pesticides uptake have undergone a change in their absorption bands intensities and frequencies confirming the participation of these functional groups in the adsorption of pesticides.

\subsection{Optimization of Experimental Parameters}

\subsubsection{Effect of $p H$}

The sample $\mathrm{pH}$ is an important monitoring parameter influencing the sorption behavior of any adsorbate onto the sorbent. The concentration of the counter ions on the functional groups of the adsorbent and the degree of ionization of the adsorbate during reaction is governed by $\mathrm{pH} .{ }^{16}$ In the present study, the effect of $\mathrm{pH}$ on the biosorption of the target pesticides was studied over different $\mathrm{pH}$ range (Fig. 3). The amount of pesticides removed at equilibrium increases with increasing $\mathrm{pH}$, appreciably up to $\mathrm{pH} 6$. Beyond $\mathrm{pH} \mathrm{6,} \mathrm{there} \mathrm{is} \mathrm{a} \mathrm{decrease} \mathrm{or}$ remains constant in the amount of pesticides removed except for malathion. A one-way ANOVA showed that variations among removal efficiency of the adsorbent for malathion at different

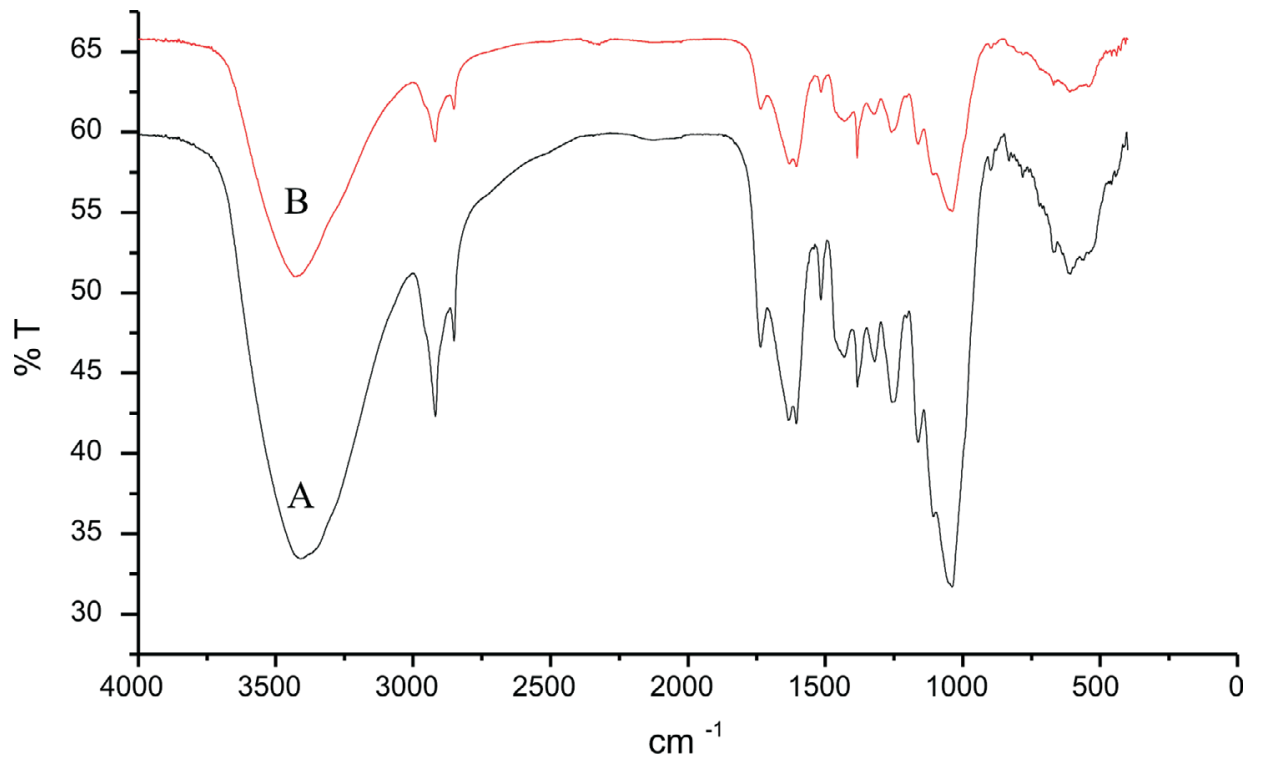

Figure 2 FTIR spectra of the adsorbent before (A) and after (B) pesticides uptake. 
$\mathrm{pH}$ were statistically insignificant $(\mathrm{P}>0.05)$. The decrease in the removal efficiency may be due to deprotonation of surface functional groups of adsorbent which results in a more negatively charged surface at higher $\mathrm{pH}$ than at the lower $\mathrm{pH}$ values. The negative charge developed at the surface of the adsorbent as a result of deprotonation cause strong electrostatic repulsion for the pesticides in solution, thereby retarding diffusion and adsorption. ${ }^{30,31}$ Hence, $\mathrm{pH} 6$ was used for all next experiments.

\subsubsection{Effect of Adsorbent Dosage}

The effect of this parameter was studied by varying the adsorbent dose from $0.1-0.5 \mathrm{~g}$. From Fig. 4, the results revealed that the influence of the adsorbent dose was significant. The amount of pesticide adsorbed was found to be increased with increasing dose to $0.4 \mathrm{~g}$ except for chlorothalonil and chlorpyrifos. The removal efficiency of chlorothalonil and chlorpyrifos were not affected by adsorbent dose in the studied range. Further increase of adsorbent dose resulted in fairly similar adsorption. The rise in removal efficiency with adsorbent dose is probably due to a stronger driving force and larger surface area. Beyond $0.4 \mathrm{~g}$ of adsorbent dose, the adsorption is slightly less resulting from lower adsorptive capacity utilization of adsorbent because the active sites of adsorbent get saturated with the available target pesticides. ${ }^{9}$ The absorption efficiency difference for malathion and dimethametryn at $0.4 \mathrm{~g}$ and $0.5 \mathrm{~g}$ of adsorbent dose is insignificant $(\mathrm{P}>0.05)$. Therefore, the optimum dose of $0.4 \mathrm{~g}$ was employed for further experiments.

\subsubsection{Effect of Contact Time}

The equilibrium time for the adsorption of the target pesticides, on the adsorbent was studied from 100 to $140 \mathrm{~min}$. As shown in Fig. 5, the removal efficiency of all the analyte
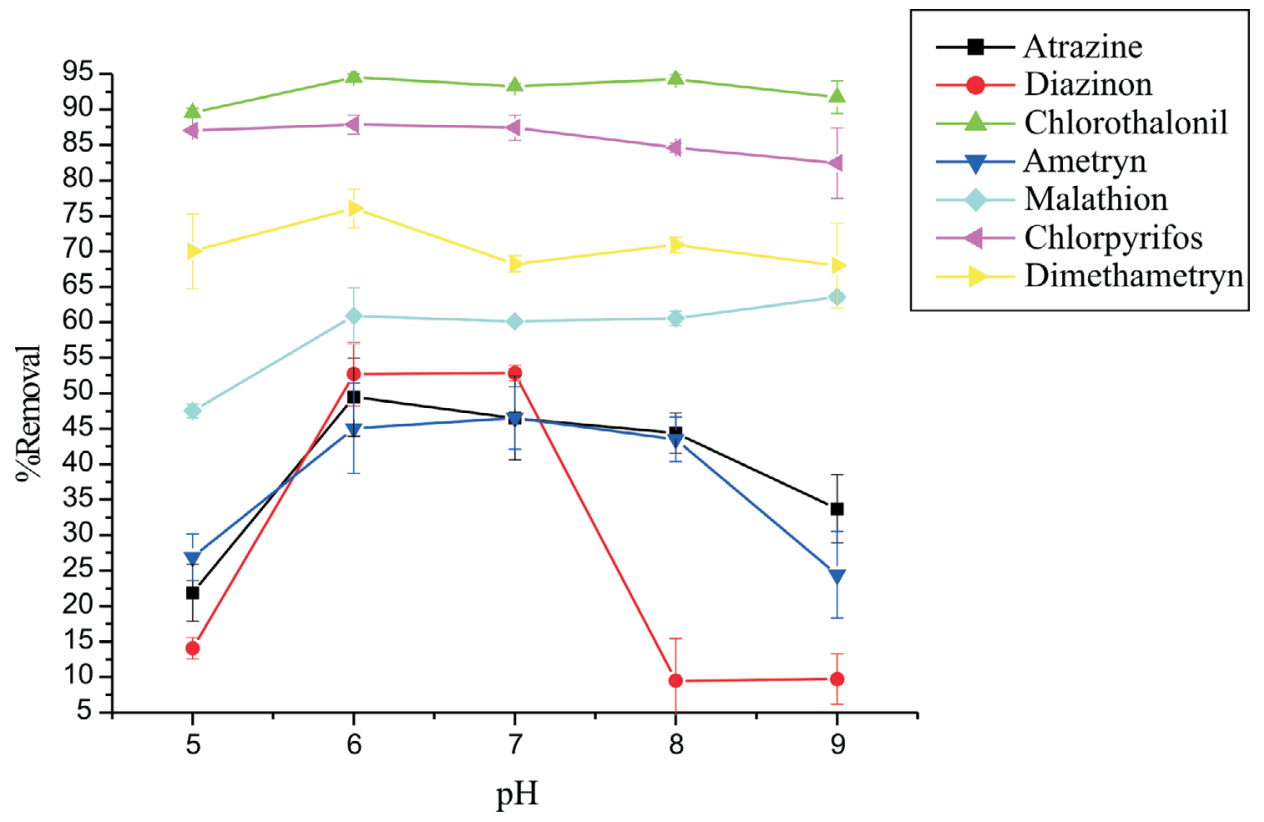

Figure 3 Effect of $\mathrm{pH}$ on uptake of pesticides by adsorbent. Experimental conditions: sample size, $50 \mathrm{~mL}$; spiked concentration, $5 \mu \mathrm{g} \mathrm{L}{ }^{-1}$; shaking speed, $150 \mathrm{rpm}$; contact time, $60 \mathrm{~min}$; adsorbent dosage, $0.5 \mathrm{~g} ; \mathrm{n}=3$.

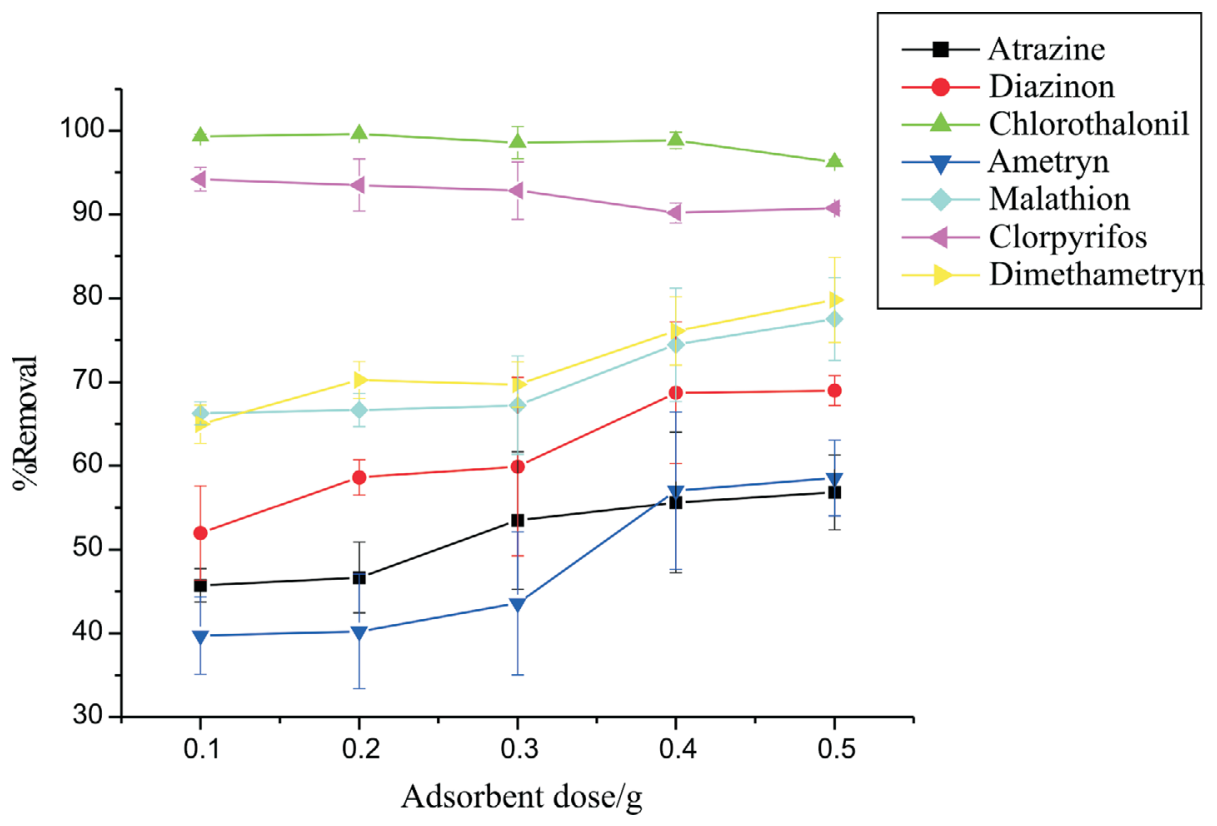

Figure 4 Effect of adsorbent dose on uptake of pesticides by adsorbent. Experimental conditions: sample size, $50 \mathrm{~mL}$; spiked concentration, $5 \mu \mathrm{g} \mathrm{L}{ }^{-1}$; $\mathrm{pH}$ 6; shaking speed, $150 \mathrm{rpm}$; contact time, $120 \mathrm{~min} ; \mathrm{n}=3$. 


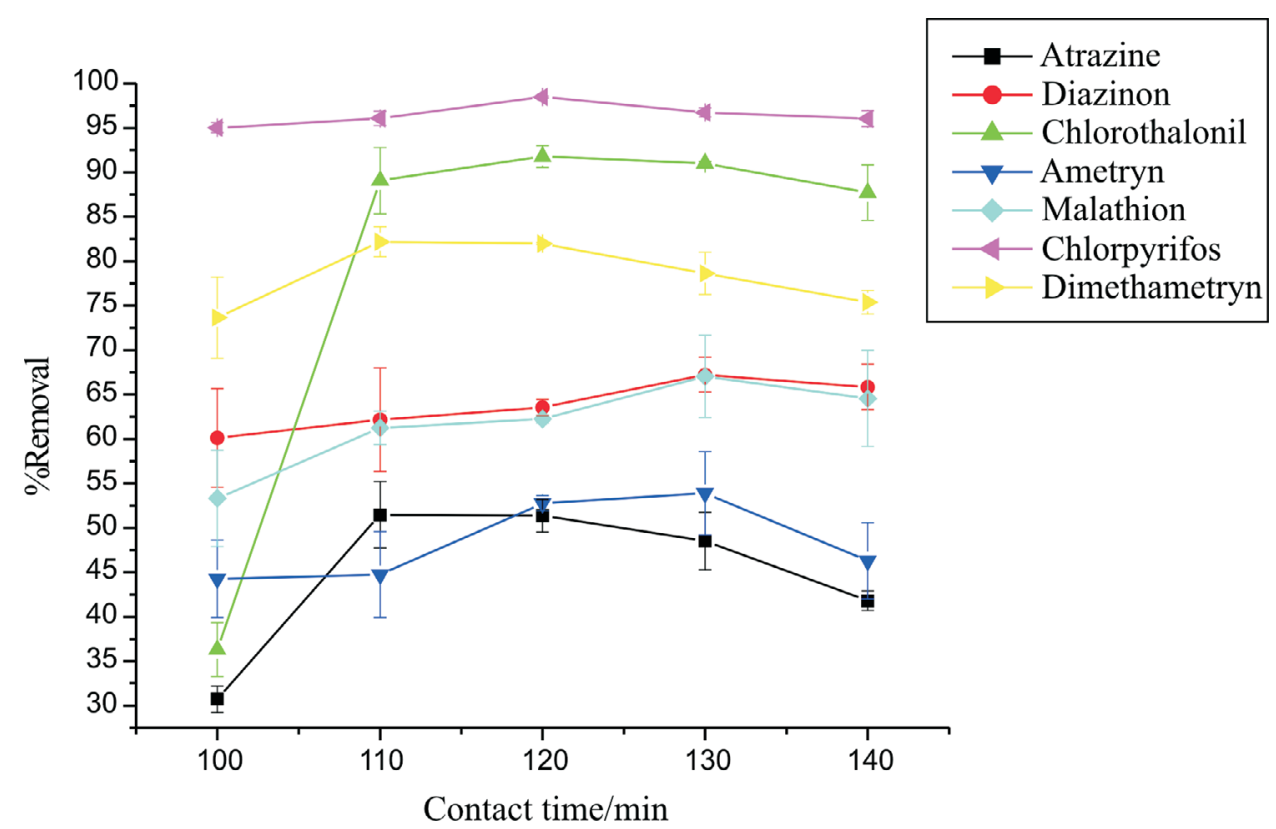

Figure 5 Effect of contact time on uptake of pesticides by adsorbent. Experimental conditions: sample size, $50 \mathrm{~mL}$; spiked concentration, $5 \mu \mathrm{g} \mathrm{L}{ }^{-1}$; $\mathrm{pH}$ 6; $150 \mathrm{rpm}$; adsorbent dosage, $0.4 \mathrm{~g} ; \mathrm{n}=3$.

considered in this study increases with adsorption time to $120 \mathrm{~min}$. However, the response remained constant for most of the pesticides after 120 min which indicates the adsorption is towards saturation. The increment of removal efficiency of diazinon, ametryn and malathion at $120 \mathrm{~min}$ and 130 is statistically insignificant $(\mathrm{P}>0.05)$. This phenomenon may be due to the vacant surface sites available for adsorption during the initial stage. On the other hand, after equilibrium is reached the other vacant surface sites were difficult to be absorbed due to repulsive forces between the adsorbate molecules on the adsorbent. ${ }^{32,33}$ Thus, the equilibrium time of $120 \mathrm{~min}$ was selected as optimum contact time for further experiments.

\subsubsection{Effect of Shaking Speed}

The removal efficiency of the adsorbent for a given sorbate generally increases with increasing the shaking speed by decreasing the boundary layer resistance to mass transfer. Furthermore, increasing shaking speed may also increases the diffusion rate of the adsorbate from the bulk into the adsorbent particles hence decreases the time required for the adsorbate to equilibrate. $^{32}$

Sorption of target pesticides was studied in the range of 100-300 rpm. As shown in Fig. 6, removal efficiency increases with the shaking speed and attains a maximum at $150 \mathrm{rpm}$ for most of the pesticides under study. This may be due to desorption of adsorbed pesticides with vigorous increase in shaking speed. ${ }^{34}$ Even though, the removal efficiency for chlorothalonil and chlorpyrifos is increasing beyond $150 \mathrm{rpm}$, a one-way ANOVA showed that the increase in removal efficiency is statistically insignificant $(\mathrm{P}>0.05)$. Therefore, it is fair to select $150 \mathrm{rpm}$ as the optimum shaking speed for subsequent experiments.

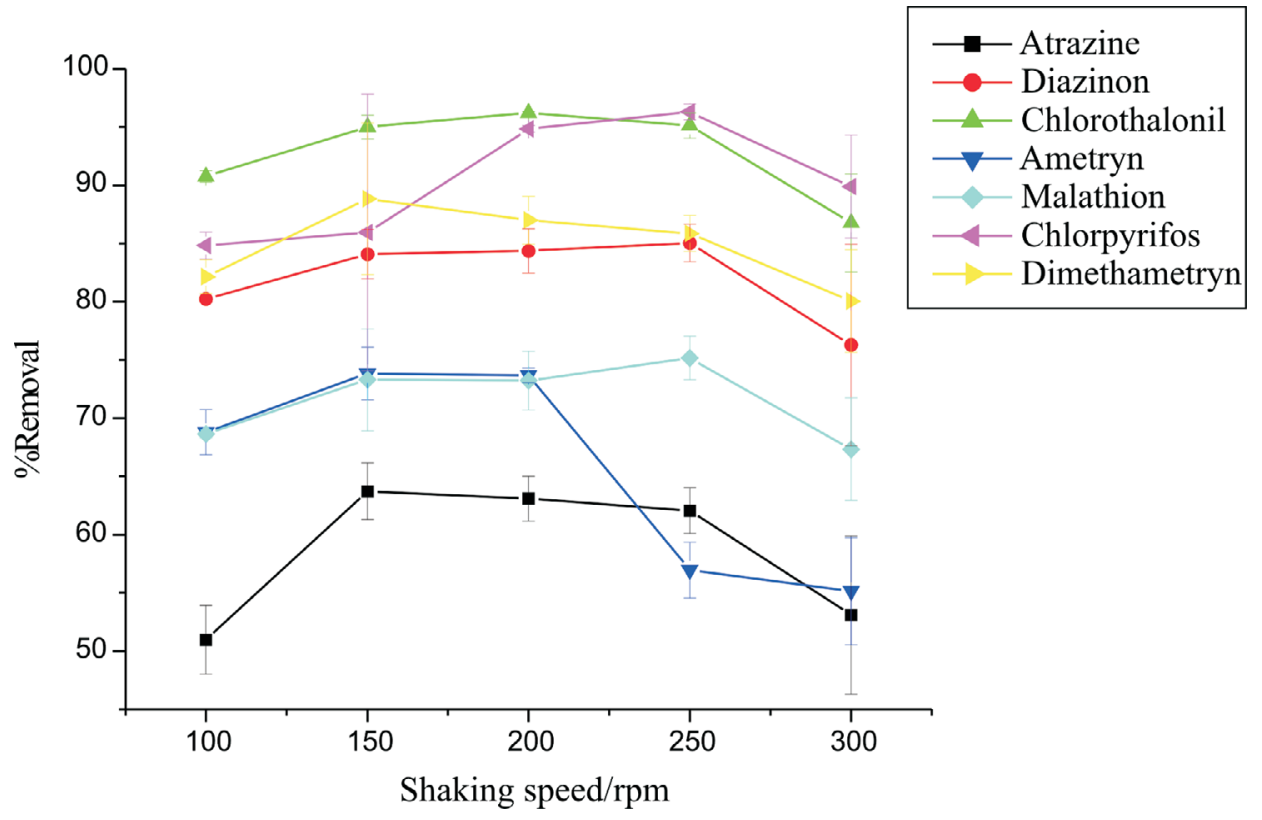

Figure 6 Effect of shaking speed on uptake of pesticides by adsorbent. Experimental conditions: sample size, $50 \mathrm{~mL}$; spiked concentration, $5 \mu \mathrm{g} \mathrm{L}{ }^{-1}$; $\mathrm{pH}$ 6; contact time, $120 \mathrm{~min}$; adsorbent dosage, $0.4 \mathrm{~g} ; \mathrm{n}=3$. 


\subsubsection{Effect of Initial Concentration of Pesticides}

The initial concentration effect of atrazine, daizinon, chlorothalonil, ametryn, malathion, chlorpyrifos and dimethametryn over the range of $0.315-100 \mu \mathrm{g} \mathrm{L}^{-1}$, on their own uptake by optimum adsorbent dose/(50 mL of sorbate solutions) were studied. As indicated in Fig. 7, increasing sorbate concentrations leads to a decrease in the removal efficiency was observed. At higher concentration of sorbate molecules, the number of available sorption sites is limited. But, the actual amount of pesticides adsorbed per unit mass of the adsorbent was increased with increase in the initial pesticides concentration. At low sorbate/ sorbent ratios, sorption involves the higher energy sites. The higher energy sites are saturated as the sorbate/sorbent ratio increases, and sorption begins on lower energy sites, resulting in a decrease in percentage removal. 3,35

\subsection{Adsorption Isotherms}

An adsorption isotherm is the graphical representation of the amount of solute adsorbed per unit weight of adsorbent as a function of the equilibrium concentration or pressure of the adsorbate in the bulk solution at constant temperature. ${ }^{29,30}$ Experiments for adsorption isotherms studies were carried out at a fixed adsorbent dose by varying adsorbate concentrations and fitness of the data to the Langmuir and Freundlich adsorption isotherms were evaluated at room temperature. ${ }^{31,35}$ In this study, the affinity between the adsorbent and pesticides were quantified by fitting the sorption results obtained to the linear Langmuir and Freundlich equations. The Langmuir isotherm model assumes monolayer coverage on homogeneous surfaces and constant adsorption energy of the process. The linear form of Langmuir isotherm model is given by Equation 3. ${ }^{31}$

$$
\frac{1}{\mathrm{q}_{\mathrm{e}}}=\frac{1}{\mathrm{q}_{\max }}+\left(\frac{1}{\mathrm{~K}_{\mathrm{L}} \mathrm{q}_{\max }}\right) \frac{1}{\mathrm{C}_{\mathrm{e}}}
$$

where $\mathrm{q}_{\mathrm{e}}\left(\mathrm{mg} \mathrm{g}^{-1}\right)$ is the equilibrium sorption capacity, $\mathrm{q}_{\max }$ $\left(\mathrm{mg} \mathrm{g}^{-1}\right)$ is the maximum sorption capacity, $\mathrm{K}_{\mathrm{L}}\left(\mathrm{L} \mathrm{mg}^{-1}\right)$ is the Langmuir constant which is related to the affinity of the binding sites for the adsorbate and $\mathrm{C}_{\mathrm{e}}\left(\mathrm{mg} \mathrm{L}^{-1}\right)$ is the equilibrium adsorbate concentration in solution. The Langmuir parameters, $\mathrm{q}_{\max }$ and $\mathrm{K}_{\mathrm{L}}$, were calculated from the intercepts and slopes, respectively, of the linear plot of $1 / \mathrm{q}_{\mathrm{e}}$ versus $1 / \mathrm{C}_{\mathrm{e}}$. Furthermore, the separation factor $\left(R_{L}\right)$, which indicates the shape of the isotherm were calculated according to Equation $4 .^{35}$

$$
\mathrm{R}_{\mathrm{L}}=\frac{1}{1+\mathrm{K}_{\mathrm{L}} \mathrm{C}_{\mathrm{i}}}
$$

Freundlich isotherm model describes the equilibrium on heterogeneous surfaces and assumes that the adsorption of sorbate takes place on the heterogeneous surface by multilayer sorption with interaction between adsorbed molecules. It is also assumed that the stronger binding sites are occupied first and that the binding strength decreases with the increasing degree of site occupation. The Freundlich parameters $\left(\mathrm{K}_{\mathrm{F}}, \mathrm{n}\right)$ were also calculated from slope and intercept, respectively, of the linear plot of $\log \mathrm{q}_{\mathrm{e}}$ versus $\log \mathrm{C}_{\mathrm{e}}$ of Equation 5.33

$$
\log \mathrm{q}_{\mathrm{e}}=\log \mathrm{K}_{\mathrm{F}}+\frac{1}{\mathrm{n}} \log \mathrm{C}_{\mathrm{e}}
$$

The Freundlich constant $\left(\mathrm{K}_{\mathrm{F}}\right)$ indicates the adsorption capacity and represents the strength of the adsorptive bond and is the heterogeneity factor representing the bond distribution and adsorption intensity. The dimensionless constant $(1 / n)$ indicating the intensity of the adsorption or surface heterogeneity and its value ranges between zero. ${ }^{36}$

All the obtained $R_{L}$ values were in between 0 and 1 which implies a favourable adsorption. Higher $R_{L}$ values at lower concentrations showed that adsorption was more favourable at lower concentrations. The results indicate that there is a linear relationship between the amounts of pesticides sorbed per unit mass of the biosorbents against the concentration of pesticides remaining in solution $\left(\mathrm{mg} \mathrm{L}^{-1}\right)$. The values of $1 / \mathrm{n}$ obtained from Freundlich model were $<1$ indicating favourable biosorptions. ${ }^{35,36}$ However, the values of the regression coefficients $\left(\mathrm{R}^{2}\right)$ depicted in Table 2 shows that the equilibrium data fitted better to the Langmuir isotherm model than the Freundlich adsorption model indicating monolayer homogeneous surface sorptions for all target analytes. ${ }^{37}$

\subsection{Adsorption Kinetics}

The kinetic models describe the adsorption mechanisms and possible rate-controlling steps such as mass transport or chemical
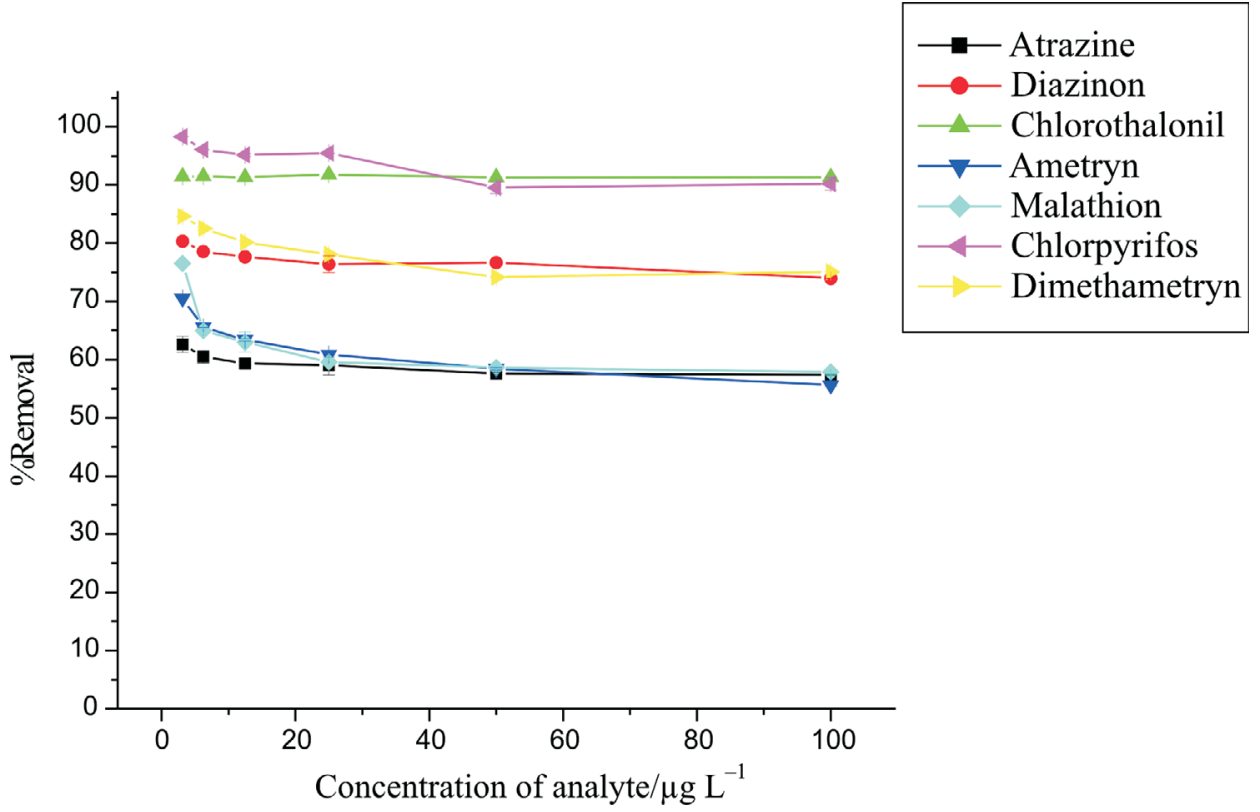

Figure 7 Effect of initial concentration on uptake of pesticides by adsorbent. Experimental conditions: sample size, 50 mL; pH 6; shaking speed, $150 \mathrm{rpm}$; contact time, $120 \mathrm{~min}$, adsorbent dose, $0.4 \mathrm{~g} ; \mathrm{n}=3$. 
Table 2 Langmuir and Freundlich adsorption parameters for the adsorption of target pesticides on adsorbent.

\begin{tabular}{|c|c|c|c|c|c|c|c|}
\hline \multirow[t]{2}{*}{ Analyte } & & \multicolumn{3}{|c|}{ Langmuir parameters } & \multicolumn{3}{|c|}{ Freundlich parameters } \\
\hline & & $\mathrm{q}_{\max } / \mu \mathrm{g} \mathrm{g}^{-1}$ & $\mathrm{R}_{\mathrm{L}}$ & $\mathrm{R}^{2}$ & $\mathrm{~K}_{\mathrm{F}}$ & $1 / n$ & $\mathrm{R}^{2}$ \\
\hline & Atrazine & 125.00 & 0.98 & 0.999 & 1.40 & 0.99 & 0.961 \\
\hline & Diazinon & 111.11 & 0.90 & 0.997 & 3.42 & 0.98 & 0.903 \\
\hline & Chlorothalonil & 1000.00 & 0.97 & 0.999 & 10.28 & 0.96 & 0.997 \\
\hline & Ametryn & 40.00 & 0.84 & 0.988 & 1.72 & 0.92 & 0.664 \\
\hline & Malathion & 22.00 & 0.68 & 0.936 & 1.99 & 0.61 & 0.476 \\
\hline & Chloropyrifos & 22.50 & 0.11 & 0.918 & 4.98 & 0.18 & 0.111 \\
\hline & Dimethametryn & 58.80 & 0.77 & 0.995 & 3.75 & 0.87 & 0.568 \\
\hline
\end{tabular}

Table 3 Pseudo-first-order and pseudo-second-order parameters for the adsorption of target pesticides on adsorbent.

\begin{tabular}{|c|c|c|c|c|c|c|c|}
\hline \multirow[t]{2}{*}{ Analyte } & \multicolumn{4}{|c|}{ Pseudo-first-order parameters } & \multicolumn{3}{|c|}{ Pseudo-second-order parameters } \\
\hline & $\mathrm{q}_{\mathrm{e}} / \mu \mathrm{g} \mathrm{g}^{-1}$ & $\mathrm{q}_{\mathrm{e}} / \mu \mathrm{g} \mathrm{g}^{-1}$ & $\mathrm{k}_{1}$ & $\mathrm{R}^{2}$ & $\mathrm{q}_{\mathrm{e}} / \mu \mathrm{g} \mathrm{g}^{-1}$ & $\mathrm{k}_{2}$ & $\mathrm{R}^{2}$ \\
\hline Atrazine & 2.57 & 5.64 & 0.023 & 0.624 & 3.28 & 0.006 & 0.9881 \\
\hline Diazinon & 3.43 & 0.72 & 0.007 & 0.464 & 3.25 & 0.024 & 0.992 \\
\hline Chlorothalonil & 4.59 & 0.04 & 0.007 & 0.072 & 4.52 & 0.074 & 0.990 \\
\hline Ametryn & 2.86 & 3.36 & 0.014 & 0.278 & 3.33 & 0.004 & 0.999 \\
\hline Malathion & 3.38 & 1.56 & 0.007 & 0.976 & 3.50 & 0.009 & 0.999 \\
\hline Chloropyrifos & 4.92 & 0.46 & 0.007 & 0.391 & 4.95 & 0.051 & 0.999 \\
\hline Dimethametryn & 4.10 & 0.89 & 0.007 & 0.684 & 4.10 & 0.021 & 0.997 \\
\hline
\end{tabular}

$\mathrm{q}^{*}$, experimental value.

reaction processes. The kinetic parameters for adsorption process were studied from variation of the contact times and analyzed using two simple kinetic models; viz., the pseudo-firstorder and pseudo-second-order models. ${ }^{27,38}$ The slope and intercept of plots of $\log \left(\mathrm{q}_{\mathrm{e}}-\mathrm{q}_{\mathrm{t}}\right)$ versus $\mathrm{t}$ graph of Equation 6 were used to obtain the first-order rate constant, $\mathrm{k}_{1}\left(\mathrm{~min}^{-1}\right)$, and equilibrium adsorption capacity, $\mathrm{q}_{\mathrm{e}}$. Similarly, the intercept and slope of the plot plots of $\mathrm{t} / \mathrm{q}_{\mathrm{t}}$ against $\mathrm{t}$ graph of Equation 7 were used to determine the numerical values of the second-order rate constant, $\mathrm{k}_{2}$ $\left(\mathrm{g}(\mathrm{mg} \min )^{<@ 150>1}\right)$, and the equilibrium adsorption capacity, $\mathrm{q}_{\mathrm{e}^{\prime}}$ respectively..$^{29,30,39}$

$$
\begin{aligned}
& \log \left(\mathrm{q}_{\mathrm{e}}-\mathrm{q} \mathrm{t}\right)=\log \mathrm{q}_{\mathrm{e}}-\frac{\mathrm{k}_{1}}{2.303} \mathrm{t} \\
& \frac{1}{\mathrm{q}_{\mathrm{t}}}=\left(\frac{1}{\mathrm{k}_{2} \mathrm{q}_{\mathrm{e}}^{2}}\right)+\frac{1}{\mathrm{q}_{\mathrm{e}}} \mathrm{t}
\end{aligned}
$$

where $\mathrm{q}_{\mathrm{t}}\left(\mathrm{mg} \mathrm{g}^{-1}\right)$ is the amount of adsorbate adsorbed at time $\mathrm{t}$.

Based on the experimental values indicated in Table 3 for various parameters, it can be concluded the value regression coefficient $\left(R^{2}\right)$ for each analyte is higher the pseudo-secondorder kinetic model than the corresponding values for pseudo-first-order kinetic model. This indicates the experimental data of the present study better fits to the pseudo-secondorder kinetic model which indicates that chemisorption is the rate-determining step in the adsorption of all pesticides on the adsorbent. ${ }^{40-43}$

\section{Conclusion}

The adsorption process for the removal of atrazine, diazinon, chlrothalonil, ametryn, chlorpytrifos and dimethametryn pesticide residues onto flower of Typha latifolia was investigated in the batch experiments. The surface properties of the biosorbent were characterized using FT-IR spectrometer. The functional groups responsible for adsorption were identified by running the biosorbent before and after loading with the target analytes. The studied biosorbents has admirable adsorption capacity for the removal of pesticides and the adsorption process was dependent on $\mathrm{pH}$, adsorbent dose, contact time, shaking speed and initial concentration for all pesticides considered in this study. The adsorption of all analytes was found to fit to the Langmuir isotherm suggesting monolayer coverage of the adsorbent surface. The kinetic study showed that the adsorption process obeyed pseudo-second-order model indicating chemi-sorption as the rate limiting step. Therefore, the flower of this plant is an effective, efficient and economic adsorbent for the removal of studied pesticides and other pesticides having related physico-chemical properties from contaminated water.

\section{Acknowledgements}

The authors would like to thank Department of Chemistry, Addis Ababa University, for the laboratory facilities and consumables provided. Both Aksum and Dire Dawa Universities are acknowledged for the sponsorship granted to Teshome Tolcha and Tura Gemechu, respectively. All expenses for the field works and pesticide standards were obtained from International Science Program (ISP); through ETH:04 project. No conflict of interest is declared by the authors.

\section{${ }^{8}$ ORCID iD}

Teshome Tolcha: (D) orcid.org/0000-0001-8668-5204

\section{References}

1 S. Wang and Y. Peng, Natural zeolites as effective adsorbents in water and wastewater treatment, Chem. Eng. J., 2010, 156, 11-24.

2 T. Ahmad, M. Rafatullah, A. Ghazali, O. Sulaiman, R. Hashim and A. Ahmad, Removal of pesticides from water and wastewater by different adsorbents, J. Environ. Sci. Health Part C, 2010, 28, 231-271.

3 G.Z. Memon, M.I. Bhanger and M. Akhtar, The removal efficiency of chestnut shells for selected pesticides from aqueous solutions, J. Coll. Inter. Sci., 2007, 315, 33-40.

4 T. Tolcha, Y. Merdassa and N. Megersa, Low-density extraction solvent based solvent-terminated dispersive liquid-liquid microextraction for quantitative determination of ionizable pesticides in environmental waters, J. Sep. Sci., 2013, 36, 1119-1127. 
5 Y. Merdassa, J. Liu, N. Megersa and M. Tessema, An efficient and fast microwave-assisted extraction method developed for the simultaneous determination of 18 organochlorine pesticides in sediment, Intern. J. Environ. Anal. Chem., 2015, 95, 225-239.

6 S. Boudesocque, E. Guillon, M. Aplincourt, F. Martel and S. Noael, Use of low-cost biosorbents to remove pesticides from wastewater, J. Environ. Qual., 2008, 37, 631-638.

7 M.H. Dehghani, Z.S. Niasar, M.R. Mehrnia, M. Shayeghi, M.A. Al-Ghouti, B. Heibati, G. McKay and K. Yetilmezsoy, Optimizing the removal of organophosphorus pesticide malathion from water using multi-walled carbon nanotubes, Chem. Eng. J., 2017, 310, 22-32.

8 J.A. Bumpus, M. Tien, D. Wright and S.D. Aust, Oxidation of persistent environmental pollutants by a white rot fungus, Sci., 1985, 228, 1434-1436.

9 A. Omri, A. Wali and M. Benzina, Adsorption of bentazon on activated carbon prepared from Lawsonia inermis wood: equilibrium, kinetic and thermodynamic studies, Arabian J. Chem., 2016, 9, S1729-S1739.

10 J. Wu, T. Luan, C. Lan, T.W.H. Lo and G.Y.S. Chan, Removal of residual pesticides on vegetable using ozonated water, Food Control., 2007, 18, 466-472.

11 E.N. Peleka and K.A. Matis, Water separation processes and sustainability, Ind. Eng. Chem. Res., 2011, 50, 421-430.

12 R. Rojas, J. Morillo, J. Usero, E. Vanderlinden and H.E. Bakouri, Adsorption study of low-cost and locally available organic substances and a soil to remove pesticides from aqueous solutions, J. Hydrol., 2015, 520, 461-472.

13 B.H. Hameed, J.M. Salman and A. L. Ahmad, Adsorption isotherm and kinetic modeling of 2,4-D pesticide on activation derived from date stones, J. Hazard Mater., 2009, 163, 121-126.

14 D.C. Adams and L.T. Watson, Treatability of s-triazine herbicide metabolites using powdered activated carbon, J. Environ. Eng., 1996, $122,327-330$

15 M. Akhtar, S.M. Hasany, M.I. Bhanger and S. Iqbal, Low cost sorbents for the removal of methyl parathion pesticide from aqueous solutions, Chemosphere, 2007, 66, 1829-1838.

16 B. Gangadhar, Y. Tharakeswar, Y. Kalyan and G.R. Naidu, Tea (Camellia sinensis) waste for the reduction of malathion and phorate in aqueous solutions, Int. J. Environ. Agri. Res., 2016, 2, 38-44.

17 V.K. Guptaa, C.K. Jain, I. Ali, S. Chandraa and S. Agarwala, Removal of lindane and malathion from wastewater using bagasse fly ash from sugar industry waste, Water Res., 2002, 36, 2483-2490.

18 N. Singh, Adsorption of herbicides on coal fly ash from aqueous solutions, J. Haz. Mat., 2009, 168, 233-237.

19 S. Chattoraj, N.K. Mondal, B. Sadhukhan, P. Roy and T.K. Roy, Optimization of adsorption parameters for removal of carbaryl insecticide using neem bark dust by response surface methodology, Water Conserv. Sci. Eng., 2016, 1, 127-141.

20 G. Tamire and S. Mengistou, Macrophyte species composition, distribution and diversity in relation to some physicochemical factors in the littoral zone of Lake Ziway, Ethiopia, Afr. J. Ecol.,2013, 51,66-77.

21 T. Manios, E.I. Stentiford and P. Millner, Removal of heavy metals from a metaliferous water solution by Typha latifolia plants and sewage sludge compost, Chemosphere, 2003, 53, 487-494.

22 W. Mnif, A.I.H. Hassine, A. Bouaziz, A. Bartegi, O. Thomas and B. Roig, Effect of endocrine disruptor pesticides, Int. J. Environ. Res. Public Health, 2011, 8, 2265-2303.

23 N. Megersa and J.Å. Jönsson, Trace enrichment and sample preparation of alkylthio-s-triazine herbicides in environmental waters using a supported liquid membrane technique in combination with high-performance liquid chromatography, Analyst, 1998, 123, 225-231.

24 Y. Merdassa, J. Liu and N. Megersa, Development of a one-step microwave-assisted extraction method for simultaneous determination of organophosphorus pesticides and fungicides in soils by gas chromatography-mass spectrometry, Talanta, 2013, 114, 227-234.

25 G. Moussavi, H. Hosseini and A. Alahabadi, The investigation of diazinon pesticide removal from contaminated water by adsorption onto $\mathrm{NH}_{4} \mathrm{Cl}$-induced activated carbon, Chem. Eng. J., 2013, 214, 172-179.

26 T. Tolcha and N. Megersa, High density solvent based dispersive liquid-liquid microextraction technique for simultaneous and selective extraction of multiclass pesticide residues in water and sugarcane juice samples, Am. J. Anal. Chem., 2018, 9, 224-244.

27 B. Singha, T.K. Naiya, A.K. Bhattacharya and S.K. Das, Cr(VI) Ions removal from aqueous solutions using natural adsorbents-FT-IR studies, J. Environ. Prot., 2011, 2, 729-735.

28 I. Oboh, E. Aluyor and T. Audu, Biosorption of heavy metal ions from aqueous solutions using a biomaterial, Leonardo J. Sci., 2009, JanuaryJune, 58-65.

29 A.C. Rozaini, C.W. Jain, K.W. Tan, L.S. Tan, A. Azraa and K.S. Tong, Optimization of nickel and copper ions removal by modified mangrove barks, Int. J. Chem. Eng. Appl., 2010, 1, 84-89.

30 S.H. Hasan, K.K. Singh, O. Prakash, M. Talat and Y.S. Ho, Removal of $\mathrm{Cr}(\mathrm{VI})$ from aqueous solutions using agricultural waste maize bran, J. Haz. Mat., 2008, 152, 356-365.

31 G. Pandhare, N. Trivedi, R. Pathrabe and S.D. Dawande, Adsorption of $\mathrm{Cr}(\mathrm{VI})$ using low-cost adsorbent as a neem leaves (Azadirachta indica) powder, Inter. J. Eng. Res. Technol., 2013, 2, 685-688.

32 S. Chowdhury and P.D. Saha, Biosorption of methylene blue from aqueous solutions by a waste biomaterial: hen feathers, Appl. Water Sci., 2012, 2, 209-219.

33 B. Rahmanifar and S.M. Dehaghi, Removal of organochlorine pesticides by chitosan loaded with silver oxide nanoparticles from water, Clean Technol. Environ. Policy, 2014, 16, 1781-1786.

34 S.C. Ibrahim, M.A.K. Honafiah and M.Z.A Yahya, Removal of cadmium from aqueous solutions by adsorption onto sugarcane bagasse, Am.-Eurasian J. Agric. Environ. Sci., 2006, 1,179-184.

35 M.A. Abdullah and A.G.D. Prasad, Kinetic and equilibrium studies for the biosorption of $\mathrm{Cr}(\mathrm{VI})$ from aqueous solutions by potato peel waste, Int. J. Chem. Eng. Res., 2009, 1, 51-62.

36 M.A. Abdullah and A.G.D. Prasad, Biosorption of nickel (II) from aqueous solutions and electroplating wastewater using tamarind (Tamarindus indica L) bark, Aust. J. Basic Appl. Sci., 2010, 4, 3591-3601.

37 W.E. Oliveira, A.S. Franca, L.S. Oliveira and S.D. Rocha, Untreated coffee husks as biosorbents for the removal of heavy metals from aqueous solutions, J. Hazard. Mater., 2008, 152, 1073-1081.

38 V. Vinodhini and N. Das, Relevant approach to assess the performance of sawdust as adsorbent of chromium(VI) ions from aqueous solutions, Int. J. Environ. Sci. Technol., 2010, 7, 85-92.

39 A.Verma, S. Chakraborty and J.K. Basu, Adsorption study of hexavalent chromium using tamarind hull-based adsorbents, Sep. Purif. Technol., 2006, 50, 336-341.

40 P.S. Kumar and K. Kirthika, Equilibrium and kinetic study of adsorption of nickel from aqueous solution onto bael tree leaf powder, J. Eng. Sci. Technol., 2009, 4, 351-363.

41 B. Tadesse, E. Teju and N. Megersa, The teff straw: a novel low-cost adsorbent for quantitative removal of $\mathrm{Cr}(\mathrm{VI})$ from contaminated aqueous samples, Desalin. Water Treat., 2014, 56, 1-12.

42 V.K. Gupta, B. Gupta, A. Rastogi, S. Agarwal and A. Nayak, Pesticides removal from wastewater by activated carbon prepared from waste rubber tire, Water Res., 2011, 45, 4047-4055.

43 M.J. Sanchez-Martin, M.S. Rodriguez-Cruz, M.S. Andrades and M. Sanchez-Camazano, Efficiency of different clay minerals modified with a cationic surfactant in the adsorption of pesticides: influence of clay type and pesticide hydrophobicity, Appl. Clay Sci., 2006, 31, 216-228. 